\title{
Earthquake prediction: feasible and useful?
}

\section{CHRISTOPHER SCHOLZ}

There has been a recent recrudescence $\frac{1,2}{2}$ of the long debate on the feasibility of short-term earthquake prediction, namely, the prediction, with a lead time of days to weeks, of the time, location and magnitude of a future event. This type of earthquake prediction is inherently difficult to research and has a chequered past, with many intriguing but fragmentary observations of possibly precursory phenomena but no scientifically based and verified successes $\stackrel{3}{ }$.

The current debate has taken the matter further, with the assertion, based on two arguments, that such prediction is intrinsically impossible. The first argument is that the Earth is in a state of self-organized criticality (SOC), everywhere near the rupture point, so that earthquakes of any size can occur randomly anywhere at any time.

SOC refers to a global state, such as that of the whole Earth or a large portion of it containing many earthquake generating faults with uncorrelated states. However, to paraphrase what Tip O'Neil, the late Speaker of the US House of Representatives, said about politics, earthquake prediction is always local.

This point is illustrated in Fig. 1, which shows the canonical sandpile model of SOC. The pile is built by a rain of sand and, when its sides reach the critical angle of repose (Fig. 1A), landslides of all sizes begin to occur. If we focus now on only one sector of the sandpile, there will occasionally occur a system-sized landslide (Fig. 1B), which brings the local slope well below the angle of repose. No landslides can then occur in this locality until the slope is built back up to the angle of repose. It is the problem of long-term earthquake prediction to estimate when this will occur

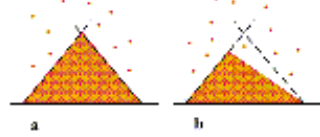

Figure 1 The sandpile model of selforganized criticality.

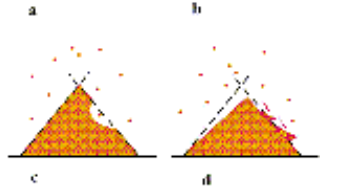

High resolution image and legend (210k)

In earthquake prediction research, this is known as the 'seismic gap' hypothesis. A test of this hypothesis ${ }^{4}$, which had negative results, was flawed because it used earthquakes that were smaller than system-sized and took only a bite out of the side (Fig. 1C), which clearly does not preclude subsequent local earthquakes.

Their second argument is based on the conjecture that an earthquake cannot 'know' how big it will become because that depends entirely on initial conditions (local state of stress and strength of the fault). This will prevent the earthquake magnitude from being predicted even if one could sense its nucleation (which friction theory predicts might be detectable days or weeks before the earthquake instability ${ }^{5}$ ).

Could this conjecture be false? There are observations that indicate that the size of foreshock zones, and a precursory slip phase of earthquakes, which might map the nucleation region, scale with the size of the subsequent mainshock $\frac{6,7}{}$. Thus the detection of the nucleation zone size might allow the prediction of the size of the subsequent earthquake. 
If, however, this conjecture is true, can it preclude the prediction of the earthquake's size? No, but the problem would then change; it would require determining the initial conditions, namely the size of the region around the nucleation zone that is loaded near the critical state. Other methods, such those espoused in the 'dilatancy-diffusion' theory of earthquake prediction ${ }^{8}$, might make that possible.

Therefore, although we do not have a method for making short-term predictions, I do not believe it is justified to assert that it is impossible. What, then, can we say about other types of earthquake prediction: their feasibility and utility?

Long-term prediction, which is the estimate, on a decadal time scale, of the probable failure time of segments of active faults, is now an established part of seismic hazard analysis ${ }^{9}$. On the basis of that methodology, several studies forecast the 1989 Loma Prieta, California, earthquake in the six years before that event $\frac{10}{}$. The utility of this kind of prediction is that with a decadal lead time, it can guide engineering and emergency planning measures to mitigate the impact of the earthquake. An intermediate-term prediction is an update of the long-term prediction brought about by an increase in seismicity (ig. 1D) or some other indicator that the fault is near its failure point.

In another type of prediction, an Immediate Alert, seismic waves above a certain threshold send an electronic alert, which, with a lead time of several seconds, can be used for such things as shutting down nuclear reactors, gas and electricity grids, and the like. A system like this is in use in Japan to stop high-speed trains in the event of an earthquake.

Finally, the finding that earthquakes often trigger other earthquakes on nearby faults leads to another prediction model, which might be called a postearthquake seismic hazard reassessment. In this methodology, shortly after a large earthquake the resulting stress changes are calculated on all nearby faults and warnings issued about those faults that have been brought closer to failure by the preceding earthquake ${ }^{11}$.

What, then, should we do about short-term earthquake prediction? Should we declare it impossible and banish it from our minds? I think not: there is much yet to be learned about earthquake physics, and rapid progress is being made, particularly in the applications of the rate/state variable-friction laws to the problem $\stackrel{12}{ }$. Until now we have been working in the dark, with the only observables being the earthquakes themselves. Dense permanent global positioning system(GPS) networks are presently being installed in California and Japan and elsewhere that, together with satellite radar interferometry, will allow us to view for the first time the evolution of strain fields in space and time. Who knows what might turn up? Then there are the curious 'precursory' phenomena, which continue to be serendipitously observed from time to time. What could their mechanism be?

\section{Christopher H. Scholz}

Lamont-Doherty Earth Observatory, Columbia University, Palisades, New York, USA

\section{References}

1. Main, I.G. Long odds on prediction. Nature 385, 19-20 (1997).

2. Geller, R.J., Jackson D.D., Kagan, Y.Y. \& Mulargia, F. Earthquakes cannot be predicted. Science 275, 1616-1618 (1997).

3. Schol, C.H. Whatever happened to earthquake prediction. Geotimes, pp. 16-19, March (1997).

4. Kagan, Y.Y. \& Jackson, D.D. Seismic gap hypothesis: ten years after. J. Geophys. Res. 96, 21419-21431 (1991).

5. Dieterich, J.H. \& Kilgore, B. Implications of fault constitutive properties for earthquake prediction. Proc. Natl Acad. Sci. USA 93, 3787-3794 (1996).

6. Dodge, D.A., Beroza, G.C. \& Ellsworth, W.L. Detailed observation of 
California foreshock sequences: implications for the earthquake initiation process. J. Geophys. Res. 101, 22371-22392 (1996).

7. Ellsworth, W.L. \& Beroza, G.C. Seismic evidence for an earthquake nucleation phase. Science 268, 851-855 (1995).

8. Schol, C.H., Sykes, L.R. \& Aggarwal, Y.P. Earthquake prediction, a physical basis. Science 181, 803-809 (1973).

9. Working group on California Earthquake Probabilities. Probabilities of Large Earthquakes Occurring in California on the San Andreas Fault (U.S. Geol. Surv. Open-file Rep. 88-398, 1988).

10. Harris, R.A. Forecasts of the 1989 Loma Prieta, California, earthquake. Bull. Seismol. Soc. Am. 88, 898-916 (1998).

11. Toda, S., Stein, R.S., Reasenberg, P.A., Dieterich, J.H. \& Yoshida, A. Stress transfer by the $1995 \mathrm{Mw} 6.9$ Kobe, Japan, shock: effect on aftershocks and future earthquake probabilities. J. Geophys. Res. 103, 24543-24565 (1998).

12. Schol, C.H. Earthquakes and friction laws. Nature $\underline{391,37-42}$ (1998).

Nature@ Macmillan Publishers Ltd 1999 Registered No. 785998 England. 